\title{
Serum Gastric Biomarker Levels After Sleeve Gastrectomy and Roux-en-Y Gastric Bypass Operations: A Prospective Study with 1-year Follow-up
}

\author{
Jaanus Suumann ${ }^{1}$, Toomas Sillakivi ${ }^{1}$, Živile Riispere ${ }^{2}$, Kari Syrjänen ${ }^{3}$, Pentti Sipponen ${ }^{4}$, \\ Ülle Kirsimägi ${ }^{1}$, Ants Peetsalu ${ }^{1}$
}

\author{
Corresponding author: \\ Toomas Sillakivi, MD, PhD, \\ Department of Surgery, University \\ of Tartu, Puusepa 8, Tartu, Estonia \\ Phone: +37253318082 \\ E-mail: toomas.sillakivi@kliinikum.ee
}

\section{Abbreviations:}

GP - GastroPanel;

LSG - Laparoscopic Sleeve Gastrectomy; LRYGB - Laparoscopic Roux-en-Y gastric bypass;

Pgl - Pepsinogen I;

Pgll - Pepsinogen II;

G17b - Basal (fasting) Gastrin 17;

G17s - Stimulated amidated Gastrin 17;

HPAB - Helicobacter pylori antibodies;

\%EWL - Percentage of Excess Weight

Loss;

EWL - Excess weight loss;

BMl - Body mass index;

USS - Updated Sidney System;

LA - Los Angeles classification of esophagitis;

EGDS - Esophagogastroduodenoscopy.
'Department of Surgery, University of Tartu, Tartu, Estonia 2Department of Pathology, University of Tartu, Tartu, Estonia ${ }^{3}$ Department of Clinical Research, Biohit Oyj, Helsinki, Finland ${ }^{4}$ Patolab Oy, Espoo, Finland

\section{ABSTRACT}

Objectives: To study the function of the gastric mucosa and acid secretion after bariatric surgery, GastroPanel ${ }^{\boxplus}(G P)$, serum biomarker test was performed in 29 laparoscopic sleeve gastrectomy (LSG) and 28 laparoscopic Roux-en-Y gastric bypass (LRYGB) patients before and after surgery.

Methods: Pepsinogen I (PGI), II (PGIl), basal fasting gastrin-17 (G17b), stimulated gastrin-17 (G17s) and Helicobacter pylori antibody (HPAB) levels in serum were assayed preoperatively, postoperatively on days 1 and 3 , and after 1,3 and 12 months.

Results: The serum levels of PGI, PGIl and the PGI/PGIl ratio declined significantly in the LSG patients immediately after surgery, and the low levels remained stable throughout the 1-year follow-up period. This was accompanied by a substantially increased output of G17b. In the LRYGB patients, PGI and PGIl levels rose markedly during the first 3 postoperative days, thereafter the levels of PGI and PGIII, and the PGI/PGIl ratio declined significantly. In contrast to $L S G$, the level of the G17b remained unchanged throughout the whole follow-up period in the LRYGB patients. Excess Weight Loss (\%EWL) was $77 \%$ and $65 \%$ in the LSG and LRYGB groups, respectively. The preoperative biomarker profile did not correlate with \%EWL in either of the operative groups.

Conclusions: Significant changes do occur in GP biomarker levels following LSG and LRYGB, suggesting reduced functional activity of the gastric corpus with consequent hypoacidity in the gastric remnant, particularly after LSG. Preoperative GP biomarker levels do not predict postoperative \%EWL.

Key words: Morbid obesity, bariatric surgery, gastroscopy, serological biomarkers, test accuracy, GastroPanel.

\section{INTRODUCTION}

Bariatric (weight loss) surgery is an effective treatment of morbid obesity and the number of bariatric operations has increased substantially in recent decades. The two major currently used weight loss surgeries are laparoscopic 
sleeve gastrectomy (LSG) and laparoscopic Roux-en-Y gastric bypass (LRYGB) (1-3). The fundamental difference between these two operations is that in LSG only the anatomy of the stomach is changed, due to a large vertical gastric resection, without bypassing the stomach, in contrast to LRYGB (4). The sequelae in gastric physiology caused by bariatric operations are persistent and will act over many postoperative years.

Therefore, comparison of these two surgical procedures will provide a unique opportunity to study how they influence (or change) the regulation of gastric physiology and body weight, as well as the resolution of comorbid diseases. In general, gastric surgery, like gastric vagotomies, or partial gastric resections in peptic ulcer cases, will markedly alter the secretory functions of gastric remnants, as has been demonstrated in a number of studies (5-7). The knowledge of changes in gastric physiology after bariatric surgery is, however, still limited (8-9).

Stomach-specific biomarkers provide a new noninvasive option to evaluate the stomach mucosa and gastric physiology (10-13). The latest innovation in this technology represents a panel of 4 stomach-specific biomarkes: Pepsinogen I (PGI), Pepsinogen II (PGII), Gastrin 17 (G17) and Helicobacter pylori antibody HPAB (13). Based on the blood plasma levels of these biomarkers, valuable conclusions can be drawn about the structure and function of the gastric antral and corpus mucosa, including the status of acid output in nonoperated patients. PGI is produced by chief cells in the corpus mucosa and is an indicator of the structure and function of the corpus mucosa: low level of PGI indicates impaired secretion due to mucosal atrohpy, i.e., loss of oxyntic parietal cells (14). G17 is produced by antral G-cells and its level reflects the function of the antral mucosa: low values of basal and stimulated G17 indicate antrum atrophy while low level of basal G17 alone is typical of high gastric acid output in an otherwise normal corpus mucosa (i.e., no atrophy). PGII is produced by mucous neck cells; it is a biomarker that reflects the status of the entire gastric mucosa and is particularly sensitive to inflammation. The HPAB test provides serological evidence of exposure to $H$. pylori (past or ongoing).

The applicability of this test (,,serological biopsy“) for operated gastric patients has not been established. Only limited data is available on gastric bypass patients $(8,15)$ while systematic studies have not been performed. Our previous study showed marked deviations from normal biomarker (PGI and II, G17) values (in some patients reaching the levels encountered in gastric mucosal atrophy) in LSG and LRYGB patients on average 2 years after operations with successful midterm results (16). However, as endoscopic and biopsy based confirmation was not provided (as in another recent study by Marchesi et al. (15)), the lack of preoperative biomarker values precluded asesssment of their postoperative dynamics.

As an extension of our previous study, we assessed whether postoperative changes in gastric biomarker levels are related to the operation type and anatomical changes only (as suggested in our previous report), or whether specific morphological alterations occur in the gastric mucosa. In addition, we also evaluated the dynamics of these biomarkers during the first postoperative year. According to a recent study by Marchesi et al. (15), there is positive correlation between decrease of body mass index (BMI) and serum PGI levels after LRYGB, making it interesting to assess whether preoperative, postoperative (at 1 year follow-up) or preoperative/postopertative rate of stomach-specific biomarkers is correlated with excess weight loss (EWL) at 1-year follow-up, i.e., to predict the percentage of Excess Weight Loss (\%EWL). And if this were the case, we would also be interested in whether a relevant test could be used as an additional tool for selecting the most appropriate operation type (LSG, LRYGB) for each bariatric patient to reach effective weight loss.

\section{MATERIALS AND METHODS}

\section{Ethics committee approval and consent to participate}

The study was approved by the Ethics Committee on Human Research of the University of Tartu: the protocol number of the study is 12089 , the approval for the study was given in Sept 2012.

Written informed consent was obtained from all patients.

\section{Study population}

The study population consisted of 57 patients scheduled to undergo bariatric operation. Patients were enrolled from Jan 2013 to Sept 2015 in a prospective study conducted at Tartu University Hospital. Altogether, 29 LSG and 28 LRYGB patients, matched according to preoperative $\mathrm{BMI}$, sex and age, were included in the study population. All patients were eligible for bariatric surgery: i.e., a BMI of $>40$ or $>35$, with certain obesity-related comorbidities. The key characteristics of the 29 LSG patients and of the 28 
LRYGB patients are presented in Table 1. The physical parameters (height, weight) and BMI were measured pre- and postoperatively. Total Weight Loss, decrease in $\mathrm{BMI}$ in percentage and \%EWL were calculated 1 year postoperatively.

Prior to operation, all subjects were interviewed for the history of upper abdominal complaints (dyspepsia, heartburn), tested by GastroPanel (GP), and subjected to routine esophagogastroduodenoscopy (EGDS) examination with directed biopsies.

\section{Surgical procedures}

Twenty-nine patients underwent LSG operation and 28 patients underwent LRYGB according to the standardised laparoscopic technique.

The LSG provides reduction in the gastric volume through a vertical stapler resection along the greater gastric curvature. A major part of the corpus and a small part of the antrum are resected, leaving a remnant (tubular gastric "sleeve") of $10-15 \%$ of the initial stomach, a part of both the antral and corpus. In the case of the LSG procedure, a bougie size of $35 \mathrm{Fr}$ was used and resection of the stomach was started at 3-4 $\mathrm{cm}$ from the pylorus, with a volume of the created sleeve of about $100-120 \mathrm{ml}$. The weight of the resected stomach was measured using the electronic scales, and the volume of the resected stomach was measured using a tap water test (the specimen was filled with tap water until water poured out of the created defect) as described earlier (17).

The LRYB is a combined method where, by horizontal division of the upper part of the stomach with the use of staplers, a new, smaller stomach is created, more than $90 \%$ of which is bypassed and excluded from food passage. In the case of LRYB, the volume of the created pouch is about $30-50 \mathrm{ml}$, the length of the biliopancreatic limb is $50-60 \mathrm{~cm}$ and the length of the alimentary $\operatorname{limb}$ is $120 \mathrm{~cm}$. Food is directed from this small pouch into the middle part of the small intestine through a gastro-jejunal anastomosis. No organs are removed and no resections are carried out.

\section{Biomarker tests and interpretation of test results}

The serological biomarker test (GastroPanel ${ }^{\circledR}$ test, Biohit Oyj, Helsinki, Finland) was carried out preoperatively in all patients following the manufacturer's instructions, as detailed previously (16). All samples were properly stored and transported to the service laboratory of Biohit Oyj for analysis. The GP testing was repeated on postoperative days 1 and 3 , and subsequently at 1,3 and 12 months postoperatively.

The GP is an automated ELISA test that measures the plasma levels of the following biomarkers: PGI, PGII, G17b, G17s, HPAB. The manufacturer-validated reference values of the four biomarkers are: PGI 30-160 $\mu \mathrm{g} / \mathrm{l} ;$ PGII 3-15 $\mu \mathrm{g} / \mathrm{l} ; \mathrm{PGI} / \mathrm{PGII}$ ratio 3-20, G17b 1-7pmol/l; G17s 3-30 pmol/l; HPAB<30EIU $(11,16)$.

\section{Esophagogastroduodenoscopy and histological evaluation of biopsies}

In the case of EGDS, the esophageal, gastric and duodenal mucosa was visually inspected preoperatively in all patients, and at 12 months postoperatively also in the LSG patients, for detecting abnormalities. The degree of esophagitis was evaluated according to the Los Angeles classification (LA) (18). In every patient, two biopsies from the antrum $(2 \mathrm{~cm}$ from the pyloric ring) and two biopsies from the corpus were collected. Additional biopsies were taken only when necessary. The histology of the biopsies was evaluated separately for the gastric antrum and corpus, according to the updated Sydney System (USS) classification (19), by 3 independent pathologists (ZR, KS, PS). In the case of discrepant results, the biopsies were re-evaluated by a pathologists' panel, and consensus diagnosis served as final diagnosis. HP-colonization and abundance were semi-quantitatively estimated, separately in the antral and corpus mucosa, by microscopic counting as follows: absent, mild, moderate and severe, as described earlier (20).

\section{Statistical analysis}

The data were analysed using the Statistica ${ }^{\circledR}$ version 13 software package. Continuous variables were presented as mean (M) values with standard deviation (SD), and nominal variables were presented as relative fequencies. Comparison between the groups was performed using the non-parametric Mann-Whitney $U$ test for continuous variables, where appropriate, and the Chi-square test or Fisher's exact test for nominal variables. The non-parametric Wilcoxon Signed ranks test was used for pairwise comparison of the biomarker levels preoperatively and at 1-year follow-up. The Spearman Rank test was used for estimating the correlations between gastric biomarkers and \%EWL at year 1 . All statistical tests were two-sided and $p \leq 0.05$ was considered significant. 


\section{RESULTS}

The patients of the LSG and LRYGB groups were practically identical regarding all key clinical characteristics (table 1). The \% EWL was higher in the LSG than in the LRYGB group but without statistical significance $(p=0.054)$.

\section{Biomarker changes after LSG}

Compared to their preoperative levels, the mean fasting plasma levels of PGI and PGII were abnormally low postoperatively (table 2). There was a rapid decrease in the mean PGI values during the first postoperative days reaching a minimum $(13.0 \mu \mathrm{g} / \mathrm{L})$ by the

Table 1 - The key characteristics of the LSG and LRYGP patients

\begin{tabular}{|c|c|c|c|}
\hline & $\begin{array}{r}\text { LSG group } \\
N=29\end{array}$ & $\begin{array}{r}\text { LRYGP group } \\
\mathrm{N}=28\end{array}$ & $P$ value \\
\hline \multicolumn{4}{|l|}{ Preoperatively } \\
\hline Age (years, mean \pm SD) & $42 \pm 10.7$ & $43 \pm 7.9$ & 0.776 \\
\hline Females & 21 & 20 & \\
\hline Weight $(\mathrm{kg}$, mean $\pm \mathrm{SD})$ & $127 \pm 24.0$ & $128 \pm 18.4$ & 0.909 \\
\hline Body mass index $\left(\mathrm{Kg} / \mathrm{m}^{2}\right.$, mean $\left.\pm \mathrm{SD}\right)$ & $44 \pm 5.6$ & $44 \pm 4.9$ & 0.959 \\
\hline Weight of removed gastric specimen $(\mathrm{g}$, mean $\pm \mathrm{SD})$ & $159.1 \pm 37.1$ & - & \\
\hline Volume of removed gastric specimen $(\mathrm{ml}$, mean $\pm \mathrm{SD})$ & $692.2 \pm 167.2$ & - & \\
\hline \multicolumn{4}{|l|}{ Postoperatively (1-year follow-up) } \\
\hline Weight $(\mathrm{kg}$, mean \pm SD) & $86.8 \pm 21.8$ & $92.7 \pm 15.9$ & 0.253 \\
\hline Body mass index $\left(\mathrm{Kg} / \mathrm{m}^{2}\right.$, mean $\left.\pm \mathrm{SD}\right)$ & $30.0 \pm 5.7$ & $31.6 \pm 4.6$ & 0.238 \\
\hline Excess weight loss $\%$ (mean \pm SD) & $77.3 \pm 25.4$ & $65.1 \pm 21.3$ & 0.054 \\
\hline
\end{tabular}

LSG- laparoscopic sleeve gastrectomy; LRYGP- laparoscopic Roux-en-Y gastric bypass; SD- standard deviation

Table 2 - Results of gastric biomarker analyses in LSG patients

\begin{tabular}{|c|c|c|c|c|c|c|c|c|}
\hline & Preoperative & $\begin{array}{r}1 \text { day } \\
\text { POP }\end{array}$ & $\begin{array}{r}3 \text { day } \\
\text { POP }\end{array}$ & $\begin{array}{r}1 \text { month } \\
\text { POP }\end{array}$ & $\begin{array}{r}3 \text { months } \\
\text { POP }\end{array}$ & $\begin{array}{r}12 \text { months } \\
\text { POP }\end{array}$ & $\begin{array}{r}\text { Change of } \\
\text { mean values, } \\
1 \text { year vs } \\
\text { preoperative }(\%)\end{array}$ & $\begin{array}{r}\text { P value (mean } \\
\text { preoperative } \\
\text { vs 1year POP) }\end{array}$ \\
\hline $\begin{array}{l}\text { Mean PG I } \pm \\
\text { SD (range) } \mu \mathrm{g} / \mathrm{L}\end{array}$ & $\begin{array}{r}75 \pm 30.1 \\
(34.4-154.6) \\
\end{array}$ & $\begin{array}{r}32.1 \pm 21.6 \\
(5.3-109.9)\end{array}$ & $\begin{array}{l}16.6 \pm 11.3 \\
(2.8-47.6)\end{array}$ & $\begin{array}{r}13.2 \pm 7.5 \\
(2-39.4)\end{array}$ & $\begin{array}{l}18.3 \pm 13.9 \\
(0.8-53.3)\end{array}$ & $\begin{array}{r}20.5 \pm 9.6 \\
(7.9-46.6) \\
\end{array}$ & $-73 \%$ & $<0.0001$ \\
\hline $\begin{array}{l}\text { PG I is abnormally } \\
\text { low }(<30 \mu \mathrm{g} / \mathrm{L}) \\
\text { (percentage) }\end{array}$ & $0 \%$ & $54 \%$ & $82 \%$ & $96 \%$ & $82 \%$ & $82 \%$ & & $<0.0001$ \\
\hline $\begin{array}{l}\text { Mean PG II } \pm \\
\text { SD (range) } \mu \mathrm{g} / \mathrm{L}\end{array}$ & $\begin{array}{r}6.1 \pm 4.1 \\
(1.1-16)\end{array}$ & $\begin{array}{r}3.8 \pm 2.5 \\
(1.1-12.9) \\
\end{array}$ & $\begin{array}{r}1.5 \pm 1.0 \\
(0-3.9) \\
\end{array}$ & $\begin{array}{r}2.1 \pm 1.5 \\
(0.4-6.8) \\
\end{array}$ & $\begin{array}{r}2.9 \pm 2.4 \\
(0.6-10.7) \\
\end{array}$ & $\begin{array}{r}4.3 \pm 2.9 \\
(1.3-12.8) \\
\end{array}$ & $-30 \%$ & 0.0006 \\
\hline $\begin{array}{l}\text { PG II is abnormally } \\
\text { low }(<3 \mu \mathrm{g} / \mathrm{L}) \\
\text { (percentage) }\end{array}$ & $10 \%$ & $46 \%$ & $89 \%$ & $79 \%$ & $64 \%$ & $39 \%$ & & \\
\hline $\begin{array}{l}\text { Mean PGI/PGII } \pm \\
\text { SD (range) }\end{array}$ & $\begin{array}{r}14.7 \pm 5.6 \\
(3.2-31.1)\end{array}$ & $\begin{array}{l}8.9 \pm 3.6 \\
(2.1-17)\end{array}$ & $\begin{array}{r}13.2 \pm 9.6 \\
(3.2-51.5) \\
\end{array}$ & $\begin{array}{r}8.1 \pm 5.5 \\
(2.5-28.2) \\
\end{array}$ & $\begin{array}{r}7.3 \pm 3.7 \\
(1.3-16.1)\end{array}$ & $\begin{array}{r}5.5 \pm 2.3 \\
(1.7-11.8)\end{array}$ & $-63 \%$ & $<0.0001$ \\
\hline $\begin{array}{l}\mathrm{PGI} / \mathrm{PGI} \text { is abnormally } \\
\text { low }(<3) \text { (percentage) }\end{array}$ & & $3.6 \%$ & $0 \%$ & $10.7 \%$ & $3.6 \%$ & $7.1 \%$ & & \\
\hline $\begin{array}{l}\text { Mean G17f } \pm \\
\text { SD (range) pmol/L }\end{array}$ & $\begin{array}{r}4.3 \pm 6.4 \\
(0.1-28.1)\end{array}$ & $11.8 \pm 9.5$ & $\begin{array}{r}10.1 \pm 11.8 \\
(0.01-42.3)\end{array}$ & $\begin{array}{r}6.5 \pm 7.5 \\
(0.01-26.3) \\
\end{array}$ & $\begin{array}{r}7.5 \pm 9.1 \\
(0-42) \\
\end{array}$ & $\begin{array}{r}7.9 \pm 11.2 \\
(0.1-46.5) \\
\end{array}$ & $+83 \%$ & 0.0356 \\
\hline $\begin{array}{l}\text { G17f is abnormally high } \\
(>7 \mathrm{pmol} / \mathrm{L}) \text { (percentage) }\end{array}$ & $13.8 \%$ & $60.7 \%$ & $42.9 \%$ & $32.1 \%$ & $35.7 \%$ & $32 \%$ & & \\
\hline $\begin{array}{l}\text { Mean G17s } \pm \\
\text { SD (range) pmol/L }\end{array}$ & $\begin{array}{r}9.9 \pm 9.1 \\
(0-40)\end{array}$ & & $\begin{array}{l}13.2 \pm 12.0 \\
(0.3-49.9)\end{array}$ & $\begin{array}{r}13.1 \pm 9.1 \\
(0-41.3)\end{array}$ & $\begin{array}{r}12.7 \pm 8.2 \\
(0-30.6) \\
\end{array}$ & $\begin{array}{l}14.6 \pm 12.8 \\
(0.1-45.8)\end{array}$ & $+48 \%$ & 0.0109 \\
\hline $\begin{array}{l}\text { Stimulation response } \\
\text { of } \mathrm{G} 17 \text { normal (>3 pmol/L) } \\
\text { (percentage) }\end{array}$ & $58.6 \%$ & & $14.3 \%$ & $39.3 \%$ & 33.3 & $40 \%$ & & \\
\hline $\begin{array}{l}\text { Helicobacter pylori positive } \\
\text { (percentage) }\end{array}$ & $65.5 \%$ & & & & & $53.6 \%$ & & 0.364 \\
\hline
\end{tabular}


$1^{\text {st }}$ postoperative month (lower than normal in 96\% of the cases). Thereafter a slight increase occurred at 1-year follow-up (mean $20.5 \mu \mathrm{g} / \mathrm{L}$ ), however, the mean level was still almost four times as low as the preoperative level.

Immediately after operation, the mean values of PGII decreased similarly to those of PGI but the decrease was less pronounced. The PGI/PGII ratio was in a normal range $(>3)$ in the great majority of the cases. The mean plasma fasting G17 values increased rapidly after operation at postoperative day 1 (higher than "normal" level in $60.7 \%$ of the cases). After the first month, a slight decrease was noted followed by stabilisation at 1-year follow-up (higher than normal level in $32 \%$ of the cases), although the mean levels were still almost two times as high as the preoperative levels (table 2). The mean stimulated G17 values showed a similar trend as G17f but the changes were less pronounced because of the higher G17f levels.

In the LSG group, preoperative $\mathrm{H}$. pylori seropositivity was $65.5 \%(19 / 29)$, which decreased to $53.6 \%(15 / 28)$ at 1-year follow-up.

\section{Biomarker changes after LRYGB}

Among the LRYGB patients, in whom $>90 \%$ of the stomach was not removed but was bypassed (i.e., excluded from food passage in all cases), mean PGI values increased during a short time, from postoperative day 1 to day 3 (table 3). Thereafter, the mean values decreased (lower than normal values in $58.3 \%$ of the cases) at 1-month follow-up and remained almost unchanged until 1-year follow-up (lower than normal values in $59.3 \%$ of the cases). The mean values of PGII behaved at first very similarly to those of PGI, increasing from the first postoperative day to day 3 , and decreased thereafter until postoperative month 1 . However, unlike PGI, a slight increase was noted at month 3; by 1-year follow-up, the mean PGII values had returned to the near-preoperative level. The PGI/PGII ratio was within normal limits in most cases (table 3).

The mean G17f values increased slightly immediately after operation, followed by a decline to relatively low levels, i.e., $2.5 \mathrm{pmol} / \mathrm{L}$ at year 1 . Only $11 \%$ of the cases showed abnormally high level $(>7 \mathrm{pmol} / \mathrm{l})$ of G17f at 1-year follow-up. As expected, the G17s levels were comparable to the G17f levels as no food or protein stimulus had bypassed the stomach.

Preoperative $\mathrm{H}$. pylori seropositivity in the LRYGB group was $64,3 \%$ (18/28), which decreased to $50 \%$ $(13 / 26)$ at 1-year follow-up.

Table 3 - Results of gastric biomarker analyses in LRYGP patients

\begin{tabular}{|c|c|c|c|c|c|c|c|c|}
\hline & Preoperative & $\begin{array}{l}1 \text { day } \\
\text { POP }\end{array}$ & $\begin{array}{l}3 \text { day } \\
\text { POP }\end{array}$ & $\begin{array}{r}1 \text { month } \\
\text { POP }\end{array}$ & $\begin{array}{r}3 \text { months } \\
\text { POP }\end{array}$ & $\begin{array}{r}12 \text { months } \\
\text { POP }\end{array}$ & $\begin{array}{r}\text { Change of } \\
\text { mean values, } \\
1 \text { year vs } \\
\text { preoperative }(\%)\end{array}$ & $\begin{array}{r}P \text { value (mean } \\
\text { preoperative } \\
\text { vs 1year POP) }\end{array}$ \\
\hline $\begin{array}{l}\text { Mean PG I } \pm \\
\text { SD (range) } \mu \mathrm{g} / \mathrm{L}\end{array}$ & $\begin{array}{r}84.3 \pm 44.0 \\
(22.7-186.8)\end{array}$ & $\begin{array}{r}169.8 \pm 68.4 \\
(71.2-356.4)\end{array}$ & $\begin{array}{r}200.5 \pm 61.7 \\
(70.7-400)\end{array}$ & $\begin{array}{l}33.2 \pm 21.5 \\
(1.8-91.6)\end{array}$ & $\begin{array}{r}33.9 \pm 25.6 \\
(10.8-125.3)\end{array}$ & $\begin{array}{r}32.3 \pm 20.4 \\
(11-88)\end{array}$ & $-62 \%$ & $<0.0001$ \\
\hline $\begin{array}{l}\mathrm{PG} I \text { is abnormally low } \\
(<30 \mu \mathrm{g} / \mathrm{L}) \text { (percentage) }\end{array}$ & $3.6 \%$ & $0 \%$ & $0 \%$ & $58.3 \%$ & $65.2 \%$ & $59.3 \%$ & & \\
\hline $\begin{array}{l}\text { Mean PG II } \pm \\
\text { SD (range) } \mu \mathrm{g} / \mathrm{L}\end{array}$ & $\begin{array}{r}7.9 \pm 6.9 \\
(0.3-29.3)\end{array}$ & $\begin{array}{r}17.3 \pm 11.7 \\
(3-50)\end{array}$ & $\begin{array}{l}29.7 \pm 22.4 \\
(1.7-73.3)\end{array}$ & $\begin{array}{r}3.5 \pm 3.3 \\
(0.4-16.2)\end{array}$ & $\begin{array}{r}4.4 \pm 4.2 \\
(1.1-20.6)\end{array}$ & $\begin{array}{r}6.8 \pm 5.2 \\
(1.1-20.9)\end{array}$ & $-14 \%$ & 0.5219 \\
\hline $\begin{array}{l}\mathrm{PG} \text { II is abnormally low } \\
(<3 \mu \mathrm{g} / \mathrm{L}) \text { (percentage) }\end{array}$ & $25 \%$ & $0 \%$ & $8 \%$ & $66.7 \%$ & $60.9 \%$ & $18.5 \%$ & & \\
\hline $\begin{array}{l}\text { Mean PGI/PGII } \pm \\
\text { SD (range) }\end{array}$ & $\begin{array}{r}16.9 \pm 17.7 \\
(3.9-103.4)\end{array}$ & $\begin{array}{r}12.8 \pm 6.6 \\
(4-34)\end{array}$ & $\begin{array}{l}12.5 \pm 12.1 \\
(2.7-61.8)\end{array}$ & $\begin{array}{r}12.7 \pm 9.8 \\
(0.5-49.7)\end{array}$ & $\begin{array}{r}9.9 \pm 5.4 \\
(2.6-22.7)\end{array}$ & $\begin{array}{r}5.0 \pm 3.5 \\
(1.4-13.8)\end{array}$ & $-70 \%$ & \\
\hline $\begin{array}{l}\mathrm{PGI} / \mathrm{PGIl} \text { is abnormally } \\
\text { low (<3) (percentage) }\end{array}$ & $0 \%$ & $0 \%$ & $12 \%$ & $4.2 \%$ & $4.4 \%$ & $18.5 \%$ & & 0.0016 \\
\hline $\begin{array}{l}\text { Mean G17f } \pm \\
\text { SD (range) pmol/L }\end{array}$ & $\begin{array}{r}3.55 \pm 3.38 \\
(0-12.6)\end{array}$ & $\begin{array}{r}4.11 \pm 4.83 \\
(0-23.5) \\
\end{array}$ & $\begin{array}{r}4.49 \pm 5.48 \\
(0-19.8)\end{array}$ & $\begin{array}{r}4.19 \pm 9.66 \\
(0-46.6)\end{array}$ & $\begin{array}{r}2.68 \pm 3.60 \\
(0-11.1)\end{array}$ & $\begin{array}{r}2.56 \pm 3.67 \\
(0-12.3) \\
\end{array}$ & $-28 \%$ & 0.294 \\
\hline $\begin{array}{l}\text { G17f is abnormally high } \\
(>7 \mathrm{pmol} / \mathrm{L}) \text { (percentage) }\end{array}$ & $14.3 \%$ & $24 \%$ & $20 \%$ & $12.5 \%$ & $17.4 \%$ & $11.1 \%$ & & \\
\hline $\begin{array}{l}\text { Mean stimulated G17s } \pm \\
\text { SD (range) pmol/L }\end{array}$ & $\begin{array}{r}14.4 \pm 10.9 \\
(1.5-40)\end{array}$ & & $\begin{array}{r}4.7 \pm 5.6 \\
(0.2-19.2)\end{array}$ & $\begin{array}{r}5.1 \pm 11.5 \\
(0-54.3)\end{array}$ & $\begin{array}{l}2.4 \pm 3.7 \\
(0-14.2)\end{array}$ & $\begin{array}{l}2.9 \pm 4.6 \\
(0-20.7)\end{array}$ & $-80 \%$ & $<0.0001$ \\
\hline $\begin{array}{l}\text { Stimulation response of } \\
\text { G17 normal ( }>3 \text { pmol/L) } \\
\text { (percentage) }\end{array}$ & $75 \%$ & & $16.7 \%$ & $0 \%$ & $0 \%$ & $7.4 \%$ & & \\
\hline $\begin{array}{l}\text { Helicobacter pylori positive } \\
\text { (percentage) }\end{array}$ & $64.3 \%$ & & & & & $48.2 \%$ & & 0.233 \\
\hline
\end{tabular}




\section{Endoscopic biopsy findings after LSG}

The preoperative histopathogical findings of the gastric mucosa for the LSG and LRYGB patients and the postoperative findings for the LSG patients are presented in table 4. No significant difference was observed in chronic gastritis scores (severity, activity) between the LRYGB and LGS groups preoperatively. The prevalence of HP colonization was high in both groups, at $62 \%$ and $61 \%$, respectively. Comparison of the pre- and postoperative data for the LSG group revealed no substantial changes in the chronic gastritis scores; in one case moderate degree antral mucosa atrophy had resolved; HP colonization had reduced from $62 \%$ to $44 \%$ (table 4 ).

\section{Weight loss after LSG and LRYGB}

In both study groups significant weight loss occurred at 1-year follow-up, EWL being $77.3 \%$ and $65.1 \%$ in the LGS and LGBP groups, respectively $(P=0.054)$.

\section{Association of plasma biomarker levels with postoperative excess weight loss}

According to the Spearman test, the preoperativeand 1-year follow-up levels of the gastric biomarkers (PGI, PGII G17f and G17s, HPAB) and the preoperative /1-year ratio did not correlate with \%EWL at 1 year either in the LSG or the LRYGB group (all $p=N S$ ).

\section{DISCUSSION}

Marked changes in the plasma gastric biomarker values were detected in both operated groups at 1-year follow-up.

In the LSG patients (table 2), a major decrease in PGI (and PGII) values was noted already during the first postoperative days; the values stabilised after 3 months and remained low for at least one year post- operatively. In $82 \%$ of the patients, PGI was below the reference value $(30 \mu \mathrm{g} / \mathrm{L})$, normally indicating severe atrophy of the corpus mucosa in a non-operated stomach (10,21-22).

In the LRYGB patients, the increase of PGI (and PGII) level during the first postoperative days was of short duration and can be attributed to operation related trauma. Starting from the first postoperative month until the end of the first postoperative year, the PGI values for about $60 \%$ of the patients were below the reference range (table 3 ).

The dynamics of G17f differed between the two study groups. In the case of LSG, its values were higher than the reference values in $61 \%$ of the patients at postoperative day 1 , however, by the end of the first postoperative year, the proportion of such patients had stabilised at $32 \%$ (table 2). In the LRYGB patients, the levels of G17b were low. As no protein stimulant reached the gastric antrum, there was no response of G17s to any stimulant and the levels of G17s were as low as the levels of G17b.

Our study demonstrates dynamic changes in the serum levels of the studied gastric biomarkers after operative treatment during a 1-year follow-up period. The changes were primarily caused by alterations induced by the operation and were more pronounced in the LSG than in the LRYGB patients. As confirmed by biopsies, these changes in biomarker levels did not coincide with any morphological changes in the gastric mucosa during one year of follow-up. It is important to note that in both the LSG and LRYGB groups, the mean values of the gastric biomarkers at 1-year follow-up are very similar to the corresponding values found at 2 years postoperatively in our previous study (16). Given that both studies were conducted with the same population, one can anticipate that changes in gastric biomarker levels are stable at least during a period of 1-2 years postoperatively in case there is no weight regain.

In the absence of detectable mucosal pathology, the

Table 4 - Stomach histology in the LSG and LRYGP patients

\begin{tabular}{lrrr}
\hline & $\begin{array}{r}\text { Preoperatively (LSG) } \\
\mathbf{n = 2 9}\end{array}$ & $\begin{array}{r}\text { Postoperatively (LSG) } \\
\mathbf{n}=25\end{array}$ & $\begin{array}{r}\text { Preoperatively (LRYGP) } \\
\mathbf{n = 2 8}\end{array}$ \\
\hline Histological findings: & & & \\
\hline Normal & $6(20.7 \%)$ & $2(8 \%)$ & $9(32.1 \%)$ \\
\hline Chronic gastritis & $23(79.3 \%)$ & $23(92.0 \%)$ & $19(67.9 \%)$ \\
-- with moderate or severe atrophy in corpus & $0(0 \%)$ & $0(0 \%)$ & $0(0 \%)$ \\
\hline- with moderate or severe atrophy in antrum & $1(4.3 \%)$ & $0(0 \%)$ & $3(15.8 \%)$ \\
\hline Helicobacter pylori positivity & $18(62.1 \%)$ & $11(44 \%)$ & $17(60.7 \%)$ \\
\hline
\end{tabular}

* postoperatively 4 patients in LSG group denied to undergo EGDS

LSG- laparoscopic sleeve gastrectomy; LRYGP- laparoscopic Roux-en-Y gastric bypass; EGDS- esophagogastroduodenoscopy 
obtained biomarker findings suggest "reduction" and "down-regulation" in the function of the gastric corpus in particular; one could also implicate the status of hypoacidity in fasting gastric remnants after both operations. Accordingly, in the LSG patients, the PGI and PGII levels decreased and the G17b levels increased. Such a rapid change can be explained by the fact that most of the gastric corpus in the LSG patients was resected and hence the number of PGI producing cells decreased significantly, as suggested in our previous publication (16). Through resecting a substantial proportion of the stomach corpus and fundus, also a huge parietal cell mass is removed from the corpus, resulting in a marked reduction in gastric acid output. The antral $G$ cells respond quickly to the decrease in acid output and boost their G17 output. A similar effect on $\mathrm{G} 17$ values is seen also in patients during PPI treatment: hypoclorhydria leads to the stimulation of G17 production (23). Increased G17 production is the normal function of the atrophy-free gastric antral mucosa. Acid secretion is reduced although the histology of the corpus biopsies remains unaffected. Because of hypoacidity, there may arise the risk for malabsorption of micronutrients (iron, calcium, etc) and vitaminB12 (24-26).

Differently from LSG, nothing is removed from the abdominal cavity during LRYGB operation where a small pouch created from the proximal part of the stomach is anastomosed to the small bowel leaving $90 \%$ of the primary stomach out of food passage. In the present study, changes in the gastric biomarker levels were less pronounced in this group as compared to the LSG patients (table 3). The increase of PGI and PGII in the first few postopetrative days is most likely caused by irritation (inflammation) due to surgical manipulation. At the late follow-up of the LRYGB patients, the decrease of PGI and PGII may be explained by the resting status of the stomach, as proposed also earlier (8). Also, fast food passage from the small pouch to the small intestine can even further reduce secretion in the bypassed stomach.

We noted a decrease of PGI from month 1 onwards, followed by stable, abnormally low values in $60 \%$ of the patients after one year. At the 1-year follow-up visit, the G17 values among $11 \%$ of the LRYGB patients were above the upper normal limit. It can be speculated that this is the result of a reaction due to vagotomy which decreases gastric acid secretion in the bypassed stomach.

The small pouch cannot produce PGI in adequate amounts. The reason is not atrophy of the pouch or remnant itself but the insufficient mucosal mass involved in PGI production in the pouch. At the same time, acid secretion in the bypassed stomach may still take place, since G17b is mostly within normal limits and not increased (as should be the case of the acid-free stomach). In the bypassed stomach, however, acid secretion takes place in a blind loop and does not counteract the risk of malabsorption. In fact, the risk of postoperative malabsorption must be even higher after LRYGB than after LSG.

The mean PGII values in both operation groups changed at first in parallel with the mean values of PGI, being lower at the end of the first postoperative month and increasing therafter. By the end of year 1 , the initial reduction had diminished to only $30 \%$ and $14 \%$ of the mean preoperative values in the LSG and LRYGB groups, respectively. It should be noted that PGII is produced not only in the corpus but also in the other parts of the stomach (antrum, fundus, duodenum). The above changes can be explained by mucous neck cell hyperplasia, which has been demonstrated in recent animal experiments (4).

In the present setting, the gastric mucosal pathology in the LSG group, both preoperatively and at 1-year follow-up, was mainly related to HP-associated chronic (non-atrophic) gastritis. Alterations were more pronounced in the antrum than in the corpus, which is consistent with earlier data (27). Atrophic gastritis, which invariably affects the gastric biomarker profile, was diagnosed in only one patient preoperatively but was no more detectable at 1-year follow-up. This resolution can be attributed to successful H.pylori eradication therapy, which is well documented in the literature (28). Another option, which is hard to exclude, is that atrophy in the preoperative biopsies was patchy and the right focus was missed in the follow-up biopsies. It is clear that the preoperative gastric biomarker levels were not associated with \%EWL at 1-year follow-up, which precludes the prospect to predict weight loss, or to select an appropriate operation type preoperatively on the basis of the GP biomarker profile. The GP was designed for screening for the risk of gastric cancer in asymptomatic subjects and should not be used as a screening test for gastric cancer. Similarly, as suggested by Marchesi (15), the GastroPanel test is of limited value in predicting morphological changes in the stomach mucosa after bariatric surgery, as is shown also in this study, due to the simple reason that any such morphological changes are practically non-existent (table 4). In patients who underwent bariatric surgery, the value of gastric biomarkers lies in their applicability in the follow-up period. The GastroPanel test gives an opportunity to follow up the gastric status after surgery, 
and in LSG patients, to estimate the severity of functional disturbance in acid output.

Monitoring of stomach physiology after bariatric surgery is clinically important, because the sequelae caused by resection or bypass may interfere with the welfare and health of the operated subjects in the long run. A hypoacidic stomach remnant, which is common after LSG, and bypassing of food passage in LRYGB, may impair digestion as well as the absorption of vitamins (eg. vitamin-B12), micronutrients and some pharmaceuticals (24-25).

Further studies will provide more knowledge and indices for specifying whether changes in these functions are clinically relevant or not and whether they are related, for example, to malabsorption of vitamins, micronutrients and medicines in the long term.

A weakness of our study is the lack of postoperative gastric biopsies in the LGBP group. According to other studies, however, there are no major histopathological changes either in the pouch or in the bypassed stomach during the first postoperative year (29).

\section{CONCLUSIONS}

The obtained 1-year follow-up results demonstrate that post-operative follow-up of patients who have undergone bariatric surgery can be safely conducted by repeated testing (e.g. with a 1-year interval), using the above non-invasive serological biomarker panel, without any need for endoscopy or biopsies. After one year, stomach morphology showed only insignificant morphological changes. The lower biomarker levels postoperatively reflect a reduced mass of secretory cells in the operated stomach and a down-regulation of the functional activity of the gastric corpus mucosa.

The increase of fasting G17 (G17b) after LSG suggests that in these patients, basal acid output is low and the stomach is hypochlorhydric or even achlorhydric postoperatively. In contrast, the low postoperative G17b levels in the LRYGB patients suggest that substantial basal fasting acid output may take place in the stomach remnant after LRYGB, although the plasma levels of PGI and PGII are abnormally low. Importantly, preoperative gastric biomarker levels do not correlate with EWL, indicating that operative success in attaining EWL cannot be predicted on the basis of the preoperative GP marker profile.

The follow-up of the study cohort will continue for the next five years, using a similar protocol, to establish whether the described practice of monitoring by the biomarker panel is feasible and safe also for a longer period.

\section{Authors' contributions}

JS, TS, AP, KS and PS participated in the design of the study, interpreted the data, and drafted the manuscript. JS and TS collected the clinical material. ZR, KS and PS performed, each independently, the histological evaluation of the gastric biopsies. ÜK designed and performed the statistical analyses. All authors have read and approved the final version of the manuscript.

\section{Acknowledgements}

We thank Ester Jaigma for revising the English text of the manuscript.

\section{Conflict of interest}

KS is an employee of Biohit Oyj and participated in the study as part of his assignments in the capacity of the Chief Medical Director of the company. He is not a shareholder of the company. PS is a shareholder and member of the Scientific Advisory Board of Biohit Oyj. The company develops and markets laboratory tests mainly for gastrointestinal diseases. All other authors have no conflict of interest to report.

\section{Conflicts of interest and Source of Funding}

K. Syrjänen is an employee of Biohit Oyj and participated in the study as part of his assignments as the Chief Medical Director of the company. He is not a shareholder of the company. Pentti Sipponen is a shareholder and member of the Scientific Advisory Board of Biohit Oyj. The company develops and markets laboratory tests mainly for gastrointestinal diseases. All other authors have no conflict of interest to report.

The clinical part of the study was financed by the Faculty of Medicine, University of Tartu.

\section{REFERENCES}

1. Angrisani L, Santonicola A, lovino P, Formisano G, Buchwald H, Scopinaro N. Bariatric Surgery Worldwide 2013. Obes Surg. 2015; 25(10):1822-32.

2. Abraham A, Ikramuddin S, Jahansouz C, Arafat F, Hevelone N, Leslie D. Trends in Bariatric Surgery: Procedure Selection, Revisional Surgeries, and Readmissions. Obes Surg. 2016;26(7):1371-7.

3. Kizy S, Jahansouz C, Downey MC, Hevelone N, Ikramuddin S, Leslie D. National Trends in Bariatric Surgery 2012-2015: Demographics, Procedure Selection, Readmissions, and Cost. Obes Surg. 2017; 27(11):2933-2939.

4. Arapis K, Cavin JB, Gillard L, Cluzeaud F, Lettéron P, Ducroc R et al. Remodeling of the residual gastric mucosa after roux-en-y gastric bypass or vertical sleeve gastrectomy in diet-induced obese rats. PLoS One. 2015;10(3):e0121414.

5. Peetsalu A, Tamm A, Härkönen M, Varis K, Sipponen P, Karonen SL 
et al. The effect of vagotomy and antrectomy on serum pepsinogens I and II. Scand J Gastroenterol. 1990;25(5):455-61.

6. Aärimaa M, Härkönen M, Varis K, Inberg M, Karonen SL. Serum group I pepsinogens during insulin and pentagastrin tests in unoperated and vagotomized duodenal ulcer patients. Scand $J$ Gastroenterol. 1987;22(8):956-60.

7. Sipponen P, Samloff IM, Saukkonen M, Varis K. Serum pepsinogens I and II and gastric mucosal histology after partial gastrectomy. Gut. 1985;26(11):1179-82.

8. Sundbom M, Mțrdh E, Mțrdh S, Ohrvall M, Gustavsson S. Reduction in serum pepsinogen I after Roux-en-Y gastric bypass. J Gastrointest Surg. 2003;7(4):529-35.

9. Sundbom M, Holdstock C, Engström BE, Karlsson FA. Early changes in ghrelin following Roux-en-Y gastric bypass: influence of vagal nerve functionality? Obes Surg. 2007;17(3):304-10.

10. Väänänen $H$, Vauhkonen $M$, Helske $T$, Kääriäinen I, Rasmussen $M$ Tunturi-Hihnala $\mathrm{H}$ et al. Non-endoscopic diagnosis of atrophic gastritis with a blood test. Correlation between gastric histology and serum levels of gastrin-17 and pepsinogen I: a multicentre study. Eur J Gastroenterol Hepatol. 2003;15(8):885-91.

11. Storskrubb T, Aro P, Ronkainen J, Sipponen P, Nyhlin H, Talley NJ et al. Serum biomarkers provide an accurate method for diagnosis of atrophic gastritis in a general population: The Kalixanda study. Scand. J. Gastroenterol. 2008:43(12):1448-55.

12. lijima K, Koike T, Abe Y, Ara N, Uno K, Imatani A et al. Alteration of correlation between serum pepsinogen concentrations and gastric acid secretion after H. pylori eradication. J Gastroenterol. 2009; 44(8):819-25.

13. Agreus L, Kuipers EJ, Kupcinskas L, Malfertheiner P, Di Mario F, Leja $M$ et al. Rationale in diagnosis and screening of atrophic gastritis with stomach-specific plasma biomarkers. Scand J Gastroenterol. 2012;47(2):136-47.

14. Varis K, Isokoski M. Screening of type A gastritis. Ann Clin Res. 1981;13(3):133-8.

15. Marchesi F, Tartamella F, De Sario G, Forlini C, Caleffi A, Riccò M et al. The Sleeping Remnant. Effect of Roux-En-Y Gastric Bypass on Plasma Levels of Gastric Biomarkers in Morbidly Obese Women: A Prospective Longitudinal Study. Obes Surg. 2017;27(7):1901-1905.

16. Sillakivi T, Suumann J, Kirsimägi U, Peetsalu A. Plasma levels of gastric biomarkers in patients after bariatric surgery: biomarkers after bariatric surgery. Hepatogastroenterol. 2013;60(128):2129-32 .
17. Weiner RA, Weiner S, Pomhoff I, Jacobi C, Makarewicz W, Weigand G. Laparoscopic sleeve gastrectomy--influence of sleeve size and resected gastric volume. Obes Surg. 2007;17(10):1297-305.

18. Armstrong D, Bennett JR, Blum AL, Dent J, De Dombal FT, Galmiche JP et al. The endoscopic assessment of esophagitis: a progress report on observer agreement. Gastroenterology. 1996;111(1): 85-92.

19. Dixon MF, Genta RM, Yardley, JH, Correa, P. Classification and grading of gastritis. The Update Sidney System. Am J Surg Pathol 1996;20:1161-1181.

20. Stolte M, Eidt S, Ritter M, Bethke B. Campylobacter pylori and gastritis. Pathologe. 1989;10:21-26.

21. di Mario F, Cavallaro LG. Non-invasive tests in gastric diseases. Dig Liver Dis. 2008;40(7):523-30.

22. Hartleb $M$, Wandzel $P$, Waluga $M$, Matyszczyk $B$, Bołdys $H$, Romañczyk T. Non-endoscopic diagnosis of multifocal atrophic gastritis; efficacy of serum gastrin-17, pepsinogens and Helicobacter pylori antibodies. Acta Gastroenterol Belg. 2004;67(4):320-6.

23. Agréus L, Storskrubb T, Aro P, Ronkainen J, Talley NJ, Sipponen P. Clinical use of proton-pump inhibitors but not H2-blockers or antacid/alginates raises the serum levels of amidated gastrin-17, pepsinogen I and pepsinogen II in a random adult population. Scand J Gastroenterol. 2009;44(5):564-70.

24. Schubert ML. Gastric secretion. Curr Opin Gastroenterol. 2014; 30(6):578-82.

25. Schubert ML. Functional anatomy and physiology of gastric secretion. Curr Opin Gastroenterol. 2015;31(6):479-85.

26. Sipponen $\mathrm{P}$, Laxén $\mathrm{F}$, Huotari K, Härkönen M: Prevalence of low vitamin B12 and high homocysteine in serum in an elderly male population: association with atrophic gastritis and Helicobacter pylori infection. Scand J Gastroenterol 2003;38:1209-1216.

27. Onzi TR, d'Acampora AJ, de Araújo FM, Baratieri R, Kremer G, Lyra HF Jr et al. Gastric histopathology in laparoscopic sleeve gastrectomy: pre- and post-operative comparison. Obes Surg. 2014; 24(3):371-6.

28. Zhou LY, Shen ZY, Lin SR, Jin Z, Ding SG, Huang XB et al. Changes of gastric mucosa histopathology after Helicobacter pylori eradication. Zhonghua Nei Ke Za Zhi. 2003;42(3):162-4.

29. Csendes A, Smok G, Burgos AM. Endoscopic and histologic findings in the gastric pouch and the Roux limb after gastric bypass. Obes Surg. 2006;16(3):279-83. 